Only one indicator of capillaroscopy showed significant change in the control group of patients, the presence of dilated capillaries $\left(x^{2}=5,833\right.$ with $\left.p=0,016\right)$. Conclusion: These findings suggest that treatment results were significantly better in the main study group of SS patients.

We suggest that biofeedback may be a useful adjunctive treatment for Raynaud's syndrome in patients with SS.

Disclosure of Interests: None declared

DOI: 10.1136/annrheumdis-2021-eular.1701

\section{AB0877-HPR EXERCISE COMPLIANCE AND DISEASE STATUS IN PATIENTS WITH RHEUMATIC DISEASES DURING COVID-19 PANDEMIC}

G. G. Pala ${ }^{1}$, Z. Tuna ${ }^{1}$, N. G. Tore' ${ }^{1}$, S. Bayram ${ }^{1}$, F. Sari ${ }^{1}$, M. A. Ozturk ${ }^{2}$, D. Oskay ${ }^{1}{ }^{1}$ Gazi University, Faculty of Health Sciences, Department of Physiotherapy and Rehabilitation, Ankara, Turkey; ${ }^{2}$ Gazi University, School of Medicine, Division of Rheumatology, Department of Internal Medicine, Ankara, Turkey

Background: The COVID-19 pandemic affects the whole world in many ways In an effort to slow down the infection, physical distancing and isolation policies have been implemented in Turkey, likewise the rest of the world. Thereby, rheumatic diseases require to obey the self-isolation recommendations strictly due to general vulnerability to infections in those patients. Due to the precautions taken for isolation, the physical inactivity level of the patients which would affect the disease activity has increased (1).

Objectives: The primary purpose of this study was to assess the exercise compliance and clinical status of the patients with rheumatic diseases during the COVID-19 pandemic. The secondary aim of the study was to evaluate the physical activity level and quality of life of the patients during the pandemic.

Methods: The research is a cross-sectional study. Seventy-nine patients with various rheumatic diseases were included in the study. Standard questions were used to evaluate the exercise habits, the level of pain and morning stiffness and severity of exacerbations. Pain and morning stiffness levels and attack severity were scored on a numerical rating scale (NRS) (0-10; with 0 indicating no pain/stiffness and 10 severe pain/stiffness). Attack duration was recorded in number of exacerbated days. Parameters were compared before and after the pandemic with Paired Samples T Test. The International Physical Activity Questionnaire-Short Form (IPAQ) and Nottingham Health Profile (NHP) Questionnaire were filled to assess the physical activity level and quality of life.

Results: Twenty-eight percent of the patients were diagnosed with Familial Mediterranean Fever (FMF), 37\% were Ankylosing Spondylitis (AS), 14\% were Systemic Sclerosis (ScS) 14\% were Systemic Lupus Erythematosus (SLE), $6 \%$ were Rheumatoid Arthritis, $1 \%$ were Primary Sjogren Syndrome (PSS). Less than half of the patients (46\%) did continue exercising regularly during the pandemic and $30(81 \%)$ of them performed only the exercises given by the therapist while 7 $(9 \%)$ of them tried different exercise types from another source. The reason for discontinuation to exercising expressed by the incompliant patients were mostly "unwillingness" (17 of 37 patients). Pain, morning stiffness and number of attacks were better during the pandemic compared to before however, a statistically significant difference was found only for morning stiffness $(p=.036)$. The results of IPAQ showed that the majority of the patients ( $n$ : 48$)$ were physically inactive, while only 2 patients were active during the pandemic. The most deteriorated quality of life subcategory was energy level of the patients according to the NHP scores.

Conclusion: This study results showed that patients with rheumatic diseases stayed physically inactive during the pandemic and the disease status has also been affected negatively. As the duration of the pandemic prolongs, levels of physical inactivity would increase and the progressive physical inactivity is expected to worsen patients' symptoms more. However, as the pandemic appears to continue, face-to-face exercise therapy should still be avoided. For all those reasons above, alternative ways of therapy like tele-rehabilitation would come onto stage to cope with the increasing physical inactivity of the rheumatic patients.

REFERENCES:

[1] Pinto AJ, Dunstan DW, Owen N, Bonfá E, Gualano B. Combating physical inactivity during the COVID-19 pandemic. Nature Reviews Rheumatology. 2020; 16(7):1-2.

Disclosure of Interests: None declared

DOI: 10.1136/annrheumdis-2021-eular.1746

\section{AB0878-HPR EFFECT OF AQUATIC PHYSIOTHERAPY ON PAIN AND QUALITY OF LIFE IN ELDERLY WOMEN WITH FIBROMYALGIA}

M. Antunes ${ }^{1}$, M. Vertuan ${ }^{2}$, A. Miquilin ${ }^{2}$, A. Pasqual Marques ${ }^{1}$, R. Morales ${ }^{2}$. ${ }^{1}$ University of São Paulo, Department of Physiotherapy, Speech Therapy and Occupational Therapy, São Paulo - SP, Brazil; ${ }^{2}$ Cesumar University, Physiotherapy Department, Maringá - PR, Brazil
Background: Fibromyalgia is defined as a chronic non-articular rheumatic disease, characterized by generalized, diffuse bilateral pain and the presence of tender points in specific anatomical regions. Its symptoms are characterized by a very varied picture and the etiology is considered multifactorial. Today, with difficult treatment, fibromyalgia has been a major challenge for healthcare profes sionals. Aquatic physiotherapy is currently one of the most commonly used forms of intervention in the management of fibromyalgia, and for this reason it has been used in interdisciplinary rehabilitation programs to promote health.

Objectives: To evaluate the effects of aquatic physiotherapy on pain and quality of life in patients with fibromyalgia.

Methods: This is an interventional, quasi-experimental study carried out at the Physiotherapy School Clinic of Universidade Cesumar in the city of Maringá, PR, Brazil. The study was approved by the Human Research Ethics Committee of Unicesumar under opinion No. 1,025,567. Participated in the study, elderly women aged 60 years, with clinical diagnosis of fibromyalgia. To assess the quality of life, the Medical Outcomes Study 36 - Item Short-Form Health Survey (SF-36) instrument was used and to verify the intensity of the pain, the Visual Analogue Scale was used. The aquatic physiotherapy intervention protocol was to perform 10 Watsu sessions, performed twice a week, lasting 40 minutes each. To perform the Watsu method, the following steps of the technique were followed: before starting opening, delivering the water, dancing the breath in the water, breathing balance and to finish releasing the spine. For data analysis, the Shapiro-Wilk test was initially applied to verify the normality of the variables under study. As the data presented a normal distribution, mean, standard deviation, minimum and maximum were used to characterize the results. To compare the initial and final variables the dependent student $t$ test was used. The significance adopted was $p<0.05$. Results: The study included 17 elderly women with a mean age of $67.5 \pm 4.7$ years. When comparing the evaluation and the reassessment, a statistically significant improvement was evidenced in the domains of quality of life: functional capacity $(p=0.00445)$, limitation due to physical aspects $(p=0.01347)$ pain $(p=0.00861)$, vitality $(p=0.00044)$, limitation due to emotional aspects $(p=0.02019)$, mental health $(p=0.00748)$. The domains that did not show statistical increase were the general health status $(p=0.30663)$ and the social aspects $(p=0.05037)$. The pain, on the other hand, was statistically less after the inter vention $(p=0.00059)$.

Conclusion: Aquatic physical therapy provided benefits in reducing pain and improving the quality of life of elderly women with fibromyalgia. It is important to encourage individuals with fibromyalgia to perform non-pharmacological interventions, such as aquatic physiotherapy, to promote their health and quality of life.

REFERENCES:

[1] Oliveira DV, Ferreira AAM, Oliveira DCD, Leme DEDC, Antunes MD, Nascimento Júnior JRAD. Association of the practice of physical activity and of health status on the quality of life of women with fibromyalgia. Journal of Physical Education. 2019;30(1): e3027. https://doi.org/10.4025/jphyseduc.v30i1.3027.

[2] Antunes MD, Vertuan MP. Miquilin A, Leme DEC, Morales RC, Oliveira DV. Efeitos do Watsu na qualidade de vida e quadro doloroso de idosas com fibromialgia. ConScientiae Saúde. 2016;15(4), 636-641. https://doi. org/10.5585/conssaude.v15n4.6756.

[3] Antunes M, Ferreira A, Oliveira D, Júnior JN, Bertolini S, Marques AP. There is association between the level of physical activity and quality of life of women with fibromyalgia?. Annals of rheumatic diseases. 2019;78(2)650-1. http://dx.doi.org/10.1136/annrheumdis-2019-eular.2835

Acknowledgements: This study was financed in part by the Coordenação de Aperfeiçoamento de Pessoal de Nível Superior - Brasil (CAPES) - Finance Code 001.

Disclosure of Interests: None declared

DOI: 10.1136/annrheumdis-2021-eular.2691

\section{AB0879-HPR MOTIVATION OF HEALTHCARE PROVIDERS DURING COVID19 PANDEMIC OUTBREAK}

C. Cobilinschi ${ }^{1}$, A. Constantinescu ${ }^{1}$, I. Draniceanu ${ }^{1}$, A. Balanescu ${ }^{1}$, V. Bojinca ${ }^{1}$, C. L. Constantinescu ${ }^{1}$, L. Groseanu ${ }^{1}$, S. Daia-lliescu ${ }^{1}$, I. Saulescu ${ }^{1}$, D. Mazilu ${ }^{1}$, M. Duna ${ }^{1}$, D. Opris-Belinski ${ }^{1}$, R. Ionescu ${ }^{1} .{ }^{1}$ Sf. Maria Clinical Hospital, Rheumatology and Internal Medicine, Bucharest, Romania

Background: Since the beginning of 2020, the medical staff caring for patients with rheumatic disorders has been exposed to considerable emotional and phys ical stress due to the COVID19 pandemic outbreak. Newly-designed circuits were imposed to better manage chronic patient admissions.

Objectives: To assess the level of motivation in healthcare personnel caring for patients with rheumatic disorders and identify determinants that lead to dissatisfaction during the COVID19 spread.

Methods: A 15-item questionnaire was distributed among medical and paramedical staff looking after chronic rheumatic patients. Motivation factors were included in questions having five preset answers, ranging from "not al all," "to a small extent", "moderately", "to a large extent" and "to a very large extent." The final item was an open-type question, favoring personal suggestions and potential changes in local management. 